\title{
ORIGINAL
}

\section{A solid thyroid benign nodule that showed a significant decrease in size and ultrasonographic findings mimicking papillary carcinoma during 16-year follow-up}

\author{
Yasuhiro Ito $^{1)}$, Nobuyuki Amino ${ }^{2)}$, Mitsuyoshi Hirokawa ${ }^{3)}$, Kaoru Kobayashi ${ }^{1)}$, Akihiro Miya ${ }^{1)}$ and \\ Akira Miyauchi $^{1)}$ \\ ${ }^{1)}$ Department of Surgery, Kuma Hospital, Kobe 650-0011, Japan \\ ${ }^{2)}$ Department of Internal Medicine, Kuma Hospital, Kobe 650-0011, Japan \\ ${ }^{3)}$ Department of Pathology, Kuma Hospital, Kobe 650-0011, Japan
}

\begin{abstract}
Recent advances in ultrasonography and fine needle aspiration biopsy (FNAB) have facilitated accurate diagnosis of thyroid carcinomas that require treatment. However, we often encounter nodules evaluated as malignant on ultrasonography but diagnosed as benign on cytology, for which the optimal treatment strategy remains uncertain. A 28year-old female had solitary and solid thyroid nodule measuring $6 \mathrm{~cm}$ in maximal diameter in February 1994. The lesion was cytologically diagnosed as benign. From September 1998, the nodule spontaneously decreased in size but ultrasonographic findings suspicious of malignancy such as peripheral and intra-tumoral calcification, low internal echo and irregular border gradually appeared. In July 2010, the volume of her nodule showed 97\% decrease but was evaluated as papillary carcinoma on ultrasonography. FNAB was performed again and the nodule was diagnosed as benign. When we encounter a nodule showing ultrasonographic findings suggestive of malignancy with negative cytology, we should consider the possibility of a benign nodule degenerating over time.
\end{abstract}

Key words: Thyroid nodule, Follow-up, Ultrasonography

THYROID nodule is a common disease detected in $4-7 \%$ of the general population [1]. On imaging studies, $13-50 \%$ of the population was incidentally diagnosed as having thyroid nodule and the risk of malignancy in asymptomatic nodules in the nonirradiated thyroid is $0.45 \%$ to $13 \%$ (mean $+\mathrm{SD}, 3.9+4.1 \%$ ) [2]. Recently, the elevated resolution power of ultrasonography has facilitated evaluation of nodules as benign or malignant. We established our own classification system, which is simple and useful for evaluation of nodules on mass screening of a large number of patients [3]. In combination with fine needle aspiration biopsy (FNAB), we can efficiently diagnose thyroid carcinomas that require treatment. However, we are often uncertain how to treat nodules suspicious of malignancy on ultrasonography but diagnosed as benign on cytology.

Received Oct. 20, 2010; Accepted Oct. 29, 2010 as K10E-309 Released online in J-STAGE as advance publication Nov.16, 2010

Correspondence to: Yasuhiro Ito, M.D., Ph.D., Department of Surgery, Kuma Hospital, 8-2-35, Shimoyamate-dori, Chuo-ku, Kobe 650-0011, Japan. E-mail: ito01@kuma-h.or.jp
Here, we report a case of nodule followed on ultrasonography for 16 years, which showed a significant decrease in size accompanied by definite changes suggesting papillary carcinoma on ultrasonographic findings. This case could provide a hint for management of nodules showing discrepant findings on ultrasonography and cytology.

\section{Case Report}

A 28-year-old female was referred to Kuma Hospital for examination of thyroid nodule in February 1994. On CT-scan obtained at a previous hospital, a solitary and solid nodule with regular edge extending from the isthmus to the left lobe was detected (Fig. 1-a). On ultrasonography, a solid nodule measuring more than 6 $\mathrm{cm}$ in maximal diameter showing a homogeneous internal echo and regular border was demonstrated. There was no apparent peripheral or intra-tumoral calcification. This nodule was classified as class 3 in our classification system (follicular neoplasm) [3]. This patient 
was euthyroid and her thyroglobulin (Tg) level was low at $14.2 \mathrm{ng} / \mathrm{mL}$, although her antithyroid antibodies were positive. Her Tg levels were always within normal limits during follow-up. Fine needle aspiration biopsy (FNAB) suggested adenomatous nodule or follicular adenoma, but showed no evidence of papillary carcinoma (Fig. 1-b). Surgery was recommended due to suspicion of follicular carcinoma, but the patient refused. Therefore, L-thyroxine was administered for thyroid stimulating hormone (TSH) suppression. TSH levels were kept in the low normal or lower than normal range during the administration of L-thyroxine. Ultrasonographic examination was repeated about every 6 months. In April 1995, the nodule measured $5.3 \mathrm{~cm} \times 3.0 \mathrm{~cm} \times 3.0 \mathrm{~cm}$ in size and its volume was calculated as 25 gram (long $\mathrm{x}$ wide $\mathrm{x}$ depth $\mathrm{x} \pi / 6$ ) [4] (Fig. 1-c). The volume had increased to 31.2 gram in December 1996. In September 1998, the volume was 31 gram and L-thyroixine administration was discontinued because of its ineffectiveness. However, the volume gradually and spontaneously decreased thereafter, reaching 3.0 gram in March 2004 (Fig. 1-d). Peripheral and intra-tumoral calcification appeared at that time and became clearer over time. Furthermore, border came to be irregular in a stepwise fashion. On the most recent examination in July 2010, tumor volume was further reduced to 1.1 gram $(1.7 \mathrm{~cm}$ x $1.5 \mathrm{~cm}$ $\mathrm{x} 0.8 \mathrm{~cm}$ ), but the irregularity of border came to be stronger with an increase in the low echoic lesion (Fig. 1-e). These findings were suspicious of papillary carcinoma and the lesion was classified as class 4 in our classification system, although no lymph node swelling suspected of thyroid carcinoma was not detected [3]. FNAB was again performed to rule out papillary carcinoma, but the finding was benign nodule (Fig. 1-f).

\section{Discussion}

To date, several studies regarding the natural history of thyroid nodules diagnosed as benign have been published. Kuma et al. demonstrated that $23 \%$ of single nodule enlarged, but $30 \%$ disappeared and the remaining showed no change in size on long-term follow-up for 9-11 years based on palpation [5]. Thereafter, several studies that evaluated tumor size on ultrasonography have been published, showing that $4-22 \%$ of nodules showed 50\% increase and $0-20 \%$ showed 50\% decrease in volume [6-13]. However, average follow-up periods were less than 5 years in these stud- ies and changes on ultrasonographic findings over time were not clearly described.

We succeeded in periodically following a solitary and solid nodule that showed about $97 \%$ decrease during 16-year follow-up. To our knowledge, it is rare for a solid nodule initially evaluated as follicular neoplasm to show such a decrease in size. The mechanism of this phenomenon remains unclear, but this may be because of an imbalance of proliferating cells versus cells undergoing necrosis for some reason.

Another important point is that the nodule showed a definite change in ultrasonographic findings. A novel calcification appeared, homogeneous internal echo turned to be low, and regular border came to be irregular during follow-up. These findings are indicative of papillary carcinoma and in July 2010, this nodule was graded as class 4 in our classification system [3], although cytology still suggested a benign nodule.

The discrepancy between ultrasonographic findings and FNAB cytology or pathological findings is often observed. In our series, $19.7 \%$ of nodules suspected of malignancy on ultrasonography (class 3.5 or greater) were cytologically diagnosed as benign. Even in a series of patients who underwent surgical treatment, $2.8 \%$ of nodules classified as 3.5 or greater were pathologically diagnosed as benign nodules [3]. Nodules such as that shown in this study can be misdiagnosed as carcinoma on imaging studies. In some way, this could be a limitation of diagnosis of thyroid carcinoma on ultrasonography and FNAB.

Since this patient does not undergo surgical treatment, the nodule has not been pathologically examined. We previously showed that $13.7 \%$ and $4.1 \%$ of patients who were cytologically diagnosed as benign were pathologically confirmed as papillary and follicular carcinomas, respectively [3]. Another study also showed that FNAB has a false negative rate over $10 \%$ [14]. If this patient had undergone her first medical examination in July 2010, she would have been recommended to undergo surgical treatment on suspicion of papillary carcinoma. However, this nodule showed a significant decrease in size during 16 years and FNAB findings at her first visit and in July 2010 were both negative, indicating that the possibility of malignancy is extremely low. Whatever the accurate pathology of this nodule is, it is definitely harmless for the patient and continuing observation is considered appropriate.

In this study, we showed a solitary and solid nodule that showed a significant decrease in size and ultra- 


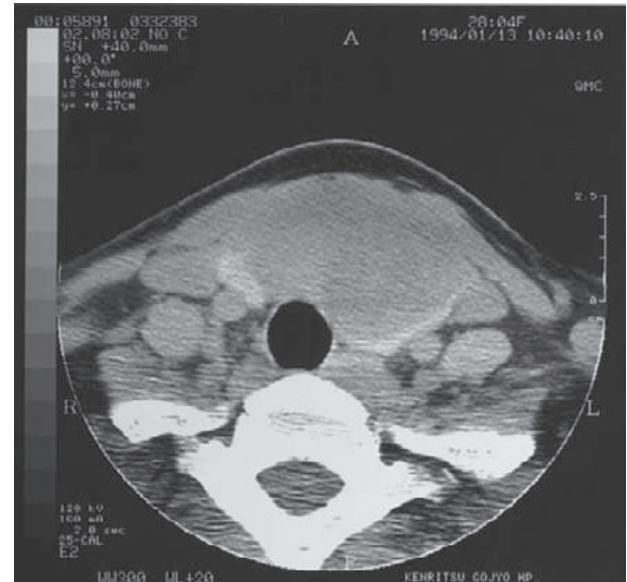

Fig. 1-a CT scan of thyroid nodule. A solid nodule was detected extending from the isthumus to the left lobe of the thyroid.

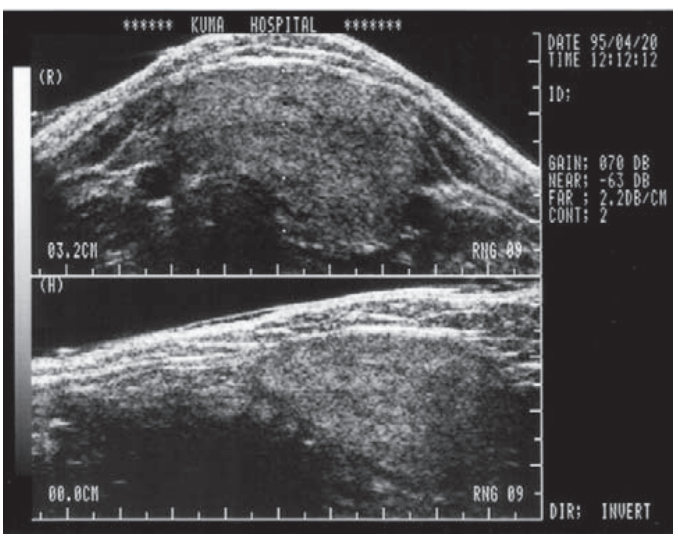

Fig. 1-c Ultrasonographic profile in April 1995. The nodule was solid, showed a homogeneous echo and regular border. It was estimated to weigh 25.0 gram.

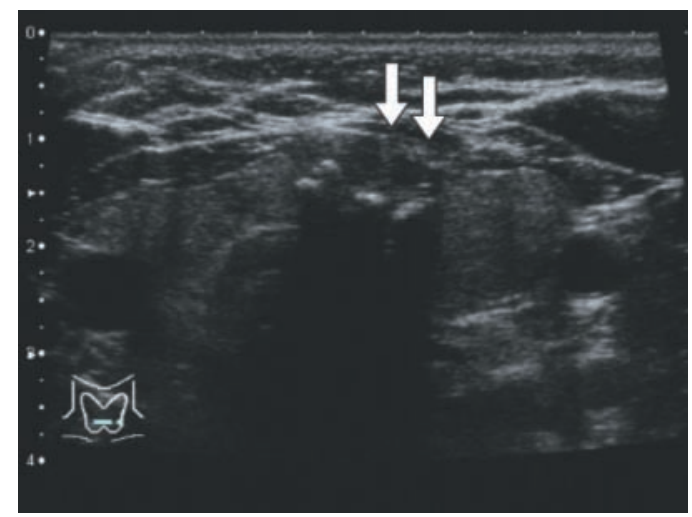

Fig. 1-e In July 2010, the nodule was estimated to weigh 1.1 gram. The low echoic lesion had increased and border irregularity became clearer. This lesion was evaluated as papillary carcinoma on ultrasonographic findings.

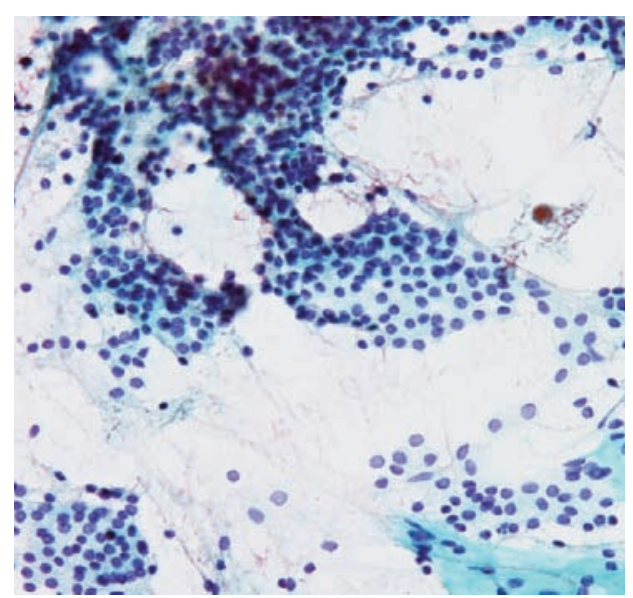

Fig. 1-b FNAB for the nodule in February 1994. The cytological diagnosis was benign lesion.

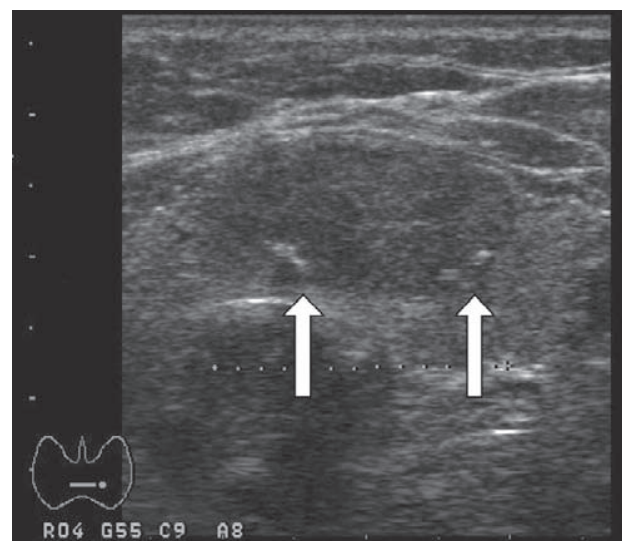

Fig. 1-d Ultrasonographic profile in March 2004. The nodule was estimated to weight 3.0 gram. It had a homogeneous echo and calcification had appeared (arrows). The border was regular.

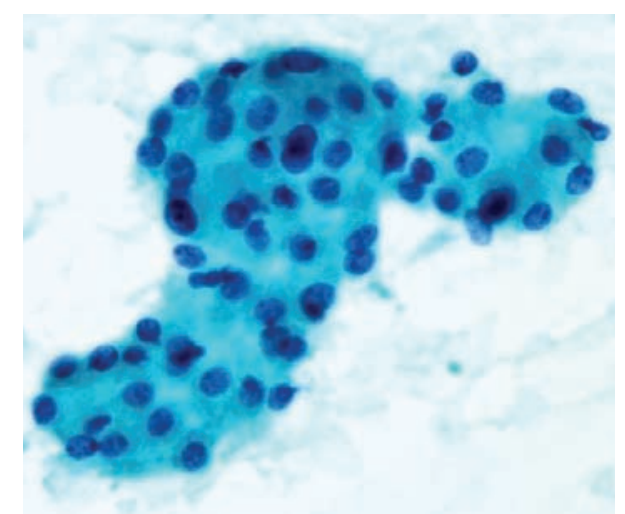

Fig. 1-f FNAB for the nodule in July 2010, which showed the similar findings as that in February 1994. 
sonographic findings mimicking papillary carcinoma during 16-year follow-up. Since no studies have been published about the change in ultrasonographic findings of benign nodules over time for large number of patients, the incidence of nodules following the course similar to this case remains unknown. However, when we encounter a nodule showing ultrasonographic find- ings suggestive of papillary carcinoma with negative cytology, we should consider the possibility of a benign nodule degenerating over time. The management of these nodules should consider other conditions such as lymph node status, compressive symptoms and change in size over time.

\section{References}

1. Rojeski MT, Gharib H (1985) Nodular thyroid disease. Evaluation and management. N Engl J Med 313: 428436.

2. Tan G, Gharib H (1997) Thyroid incidentalomas: management approaches to nonpalpable nodules discovered incidentally on thyroid imaging. Ann Intern Med 126: 226-231.

3. Ito $\mathrm{Y}$, Amino $\mathrm{N}$, Yokozawa $\mathrm{T}$, Ota $\mathrm{H}$, Ohshita $\mathrm{M}$, Murata N, Morita S, Kobayashi K, Miyauchi A (2007) Ultrasonographic evaluation of thyroid nodules in 900 patients: comparison among ultrasonographic, cytological, and histological findings. Thyroid 17: 1269-1276.

4. Knuden N, Bols B, Bulow L, Jorgensen T, Perrild H, Ovesen L, Laurberg P (1999) Validation of ultrasonography of the thyroid gland for epidemiological purposes. Thyroid 9: 1069-1074.

5. Kuma K, Matuzuka F, Yokozawa T, Miyauchi A, Sugawara M (1994) Fate of untreated benign thyroid nodules: results of long-term follow-up. World J Surg 18: 495-499.

6. Knuden N, Bols B, Bulow L, Jorgensen T, Perrild H, Ovesen L, Laurberg P (1999) Validation of ultrasonography of the thyroid gland for epidemiological purposes. Thyroid 9: 1069-1074.

7. Papini E, Bacci V, Panunzi C, Pacella C, Fabbrini R, Bizzarri G, Petrucci L, Giammarco V, La Medica P, Masala M (1993) A prospective randomized trial of levothyroxine suppressive therapy for solitary thyroid nodules. Clin Endocrinol 38: 507-513.

8. La Rosa GL, Lupo L, Giuffrida D, Gullo D, Vigneri R, Belfiore A (1995) Levothyroxine and potassium iodide are both effective in treating benign solitary solid cold nodules of the thyroid. Ann Intern Med 122: 1-8.

9. Zelmanovitz F, Genro S, Gross JL (1998) Suppressive therapy with levothroxine for solitary thyroid nodules: a double-blind controlled clinical study and cumulative meta-analysis. J Clin Endocrinol Metab 83: 38813885.

10. Wemeau JL, Caron P, Schvartz C, Schlienger ZL, Orgiazze J, Cousty C, Vlaeminck-Guillem V (2002) Effects of thyroid-stimulating hormone suppression with levothyroxine in reducing the volume of solitary thyroid nodules and improving extranodular nonpalpable changes: a randomized, double-blind, placebo-controlled trial by the French thyroid research group. J Clin Endocrinol Metab 87: 4928-4934.

11. Alexander EK, Hurwitz S, Heering J, Benson C, Frates M, Doubilet P, Cibas E, Larsen R, Marquesee E (2003) Natural history of benign solid and cystic thyroid nodules. Ann Intern Med 138: 315-318.

12. Costante G, Crocetti U, Schifino E, Ludovico O, Capula C, Nicotera M, Arturi F, Filetti S (2004) Slow growth of benign thyroid nodules after menopause: no need for long-term thyroxine suppressive therapy in postmenopausal women. J Endocrinol Invest 27: 31-36.

13. Erdogan M, Gursoy A, Erdogan G (2006) Natural course of benign thyroid nodules in a moderately iodine-deficient area. Clin Endocrinol 65: 767-771.

14. Lewis C, Chang KP, Pitman M, Faquin W, Randolph G (2009) Thyroid fine-needle aspiration biopsy: variability in reporting. Thyroid 19: 717-723. 